f. med. Genet. (1968). 5, 48.

\title{
Impaired Pronation-supination of the Forearm: An Inherited Condition*
}

\author{
J. S. THOMPSON, P. R. McLAUGHLIN, and D. J. HESLIN \\ From the Department of Anatomy, University of Toronto, and The Hospital for Sick Children Toronto, \\ Ontario, Canada
}

Davenport, Taylor, and Nelson (1924) have reported several instances of familial radio-ulnar synostoses with variable degrees of reduction in pronation and supination. Their cases fall into three general types: (1) radius without a head; (2) radial head displaced backwards; and (3) radial head more or less normal but radial shaft strongly curved.

Cockshott and Omololu (1958) reported a father and daughter with bilateral posterior dislocation of the radial head, with limitation of flexion and extension of the elbow but with normal pronation and supination. Gunn and Pillay (1964) reported a mother-daughter pair with the same deformity and limited pronation-supination.

Received June 1, 1967.

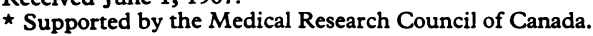

The present study concerns three generations of a Canadian family in which the affected individuals show decreased ability to pronate and supinate the forearm. In all three the radial head articulates normally with the ulna, and the curve of the shaft of the radius is within normal limits. The radial head, while exhibiting some abnormality in outline, is certainly present.

\section{Case Reports}

The propositus is a 21-year-old man of superior intelligence who, at the age of 10 , noticed that he had difficulty in manoeuvring his forearm to accept an object, say a coin, handed to him by another person. He later analysed his problem as an inability to pronate and supinate his forearms. He discovered that his father had the same problem and that the father had first noticed his impaired ability at about the age of 20 . The father reports that his father, i.e. the grandfather of the propositus, was also affected. The brother of the propositus
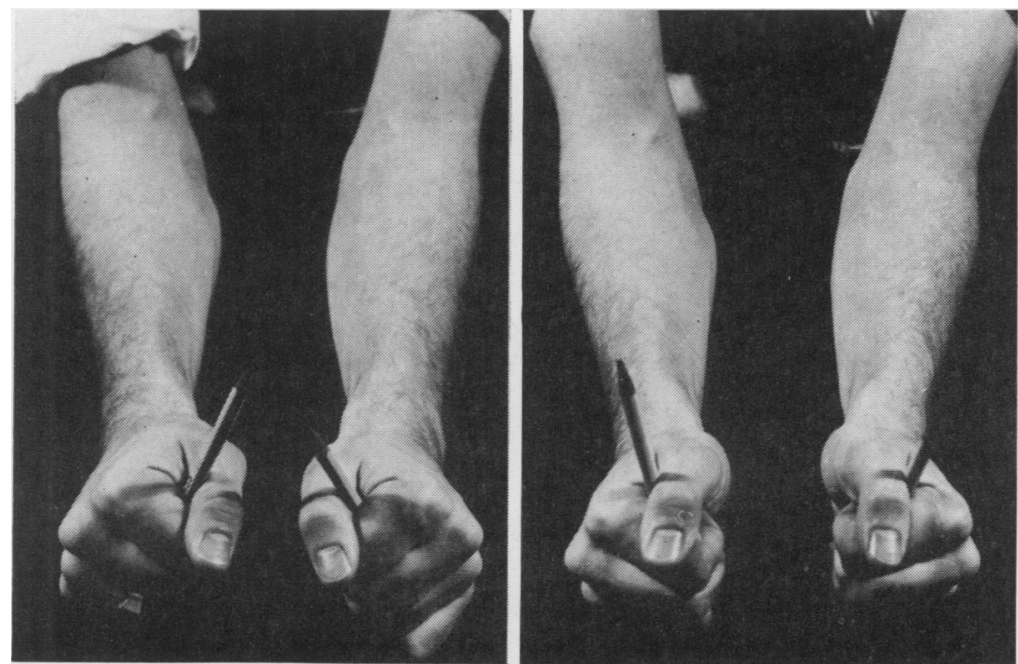

FIG. 1. The reduced ability of the propositus to pronate and supinate the forearm. Left. Full pronation. Right. Full supination. 

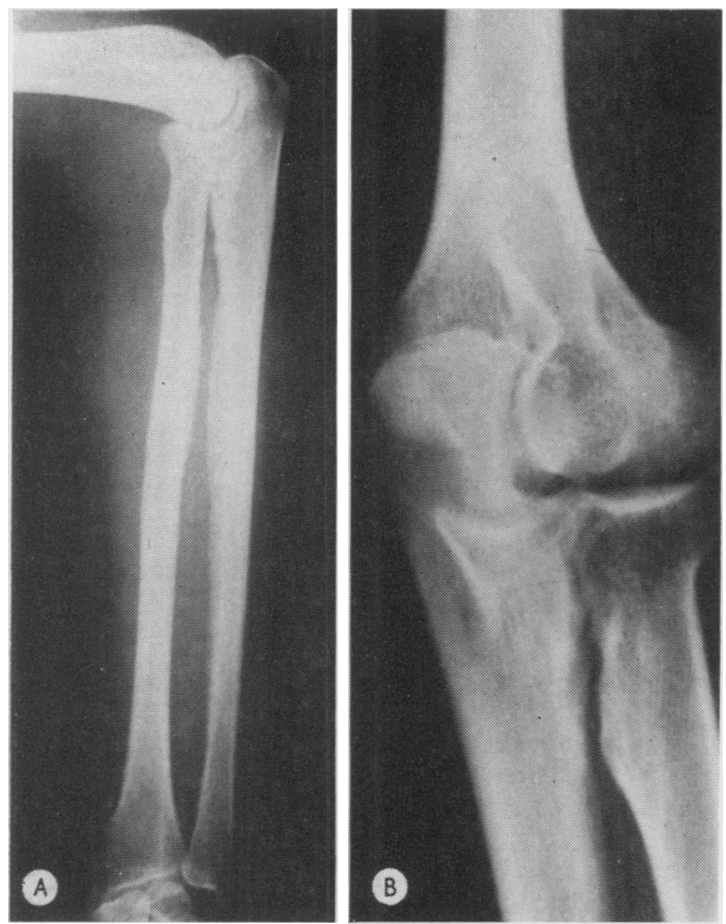

FIG. 2. $X$-ray films indicating (A) ossification of margins of interosseous membrane in aunt of propositus: note radial head in normal position; (B) upper portion forearm of propositus: note irregular outline of radial head and absence of synostoses; (C) tomograph of radius of propositus to show enlarged radial tuberosity; (D) tomograph of ulna of propositus to show lateral projection.

is perfectly normal but their paternal aunt shows a somewhat impaired ability to pronate and supinate.

It is remarkable that, in spite of a greatly reduced ability to pronate and supinate, neither the propositus nor his father has any major problem in adapting to life. Indeed, each reports that his main problem is in receiving change from a clerk in a store. Both handle a knife and fork easily and can use tools, such as screwdrivers, by rotating the humerus at the shoulder.

Physical examination of the propositus, his father, and the affected aunt reveals that each has impaired ability to pronate and supinate, as noted in the Table. It will be seen that the propositus is most severely involved and that the father, while having virtually no supination, is able to pronate reasonably well. The aunt is the least affected and, until examined by the propositus, thought her forearms were quite normal. She has compensated for her disability by a remarkable laxity of the ligaments of the wrist. Since her right forearm can supinate $60^{\circ}$, she can easily receive objects from others. The extent to which the propositus can pronate and supinate is shown in Fig. 1.

Routine antero-posterior and lateral $x$-ray films of both forearms of all three affected subjects show some abnormality, though, basically, the radii are relatively normal and their heads are not dislocated. However,
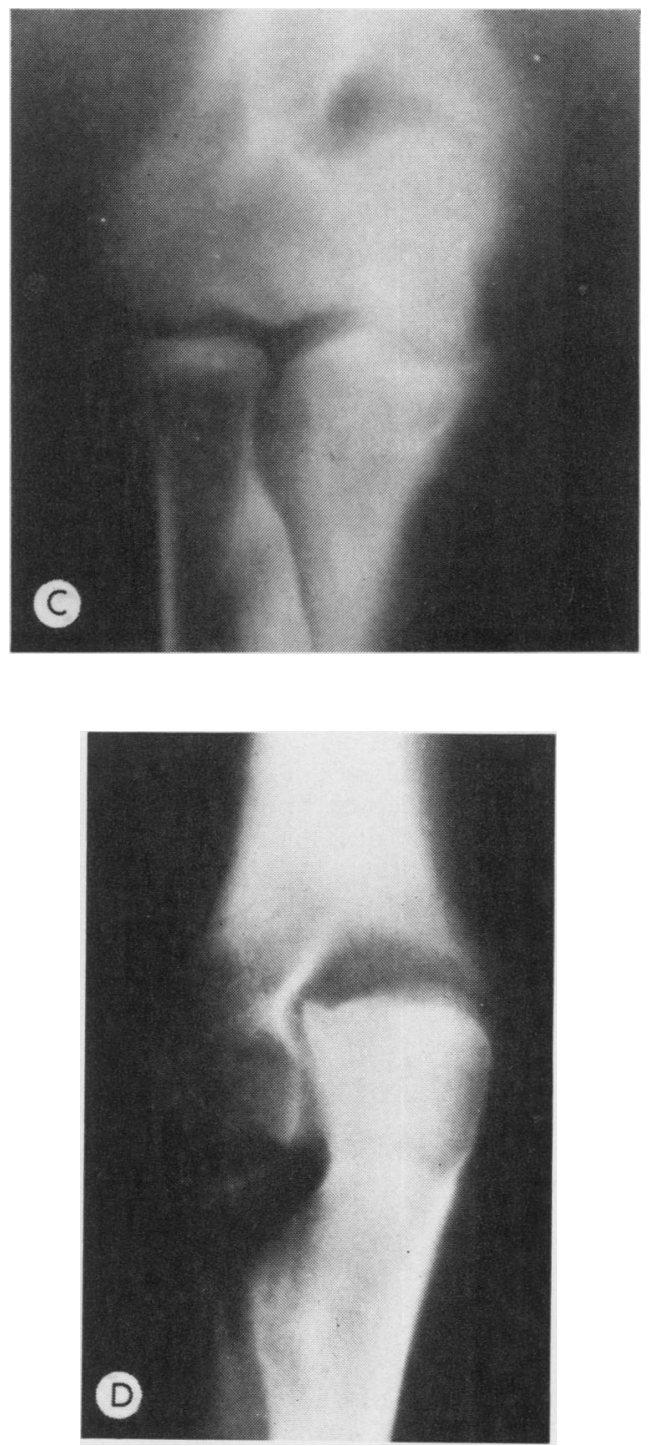

the medial surface of the radial head appears to be somewhat flattened in all three. The father and the aunt show no sign of synostosis, though there is some ossification of the margins of the interosseous membrane (Fig. 2A) where it attaches to both radius and ulna. The propositus does not show this ossification of the interosseous membrane so it may be a secondary phenomenon resulting from a long period of the relative immobility of the radius.

The propositus, while having apparently normal interosseous membranes, has such a marked inability to move the radius that routine views of the upper and lower ends of both radius and ulna are unsatisfactory because of overlap between the bones. 
TABLE

LIMITATION OF PRONATION AND SUPINATION (Normal =90 DEGREES ${ }^{\star}$ )

\begin{tabular}{|c|c|c|}
\hline & Pronation (degrees) & Supination (degrees) \\
\hline $\begin{array}{l}\text { Propositus } \\
\text { Right } \\
\text { Left } \\
\text { Father } \\
\text { Right } \\
\text { Left } \\
\text { Aunt (paternal) } \\
\text { Right } \\
\text { Left }\end{array}$ & $\begin{array}{l}15 \\
30 \\
70 \\
70 \\
40 \\
60\end{array}$ & $\begin{array}{r}0 \\
0 \\
10 \\
10 \\
60 \\
20\end{array}$ \\
\hline
\end{tabular}

$\star$ Mid prone position is regarded as $\mathrm{O}$ degrees.

Further studies, using image intensification and a television monitoring system, show that slight movement is possible between the two bones in each arm, and $x$-ray films, taken at optimal angles as shown by the television, disclose no synostoses but, especially in the right arm (the most severely affected), there are small irregularities in the outlines of the radial head and neck (Fig. 2B).

Tomographs ( $x$-ray films taken to focus on structures at specific depths) indicate that, in the right arm, the radial tuberosity is enlarged (Fig. 2C) and is overlapped posteriorly by a projection from the lateral side of the ulna (Fig. 2D) just below the radial notch. No synostosis exists between these two projections but it is possible that they are held together by connective tissue.

None of the three affected subjects shows any impairment of movement of elbow or wrist, and the biceps brachii, supinator, and pronator teres muscles all appear to be functional. No other abnormalities are reported by any of the three and all have clearly superior intelligence.

\section{Family History}

As shown in Fig. 3, the propositus, his father, and his paternal aunt are all affected, but to varying degrees. The father, an extremely intelligent man with training in genetics, reports that his father (III. 4 in Fig. 3) had a disability similar to his own. Therefore III. 4 is also considered to have been affected. Thus four members of the kindred, in three generations, have exhibited the condition. Living subjects shown as unaffected in the pedigree have all been reported to be negative, and many of these have specifically examined themselves as instructed by us. Those who carried out this selfexamination are III. 1, III. 6, III. 7, IV. 2, IV. 3, and V. 1. V. 2, the brother of the propositus, was examined and is not affected, and routine $x$-ray films of both his arms exhibit no abnormalities.

Since there is father to son transmission it is clear that the condition cannot be X-linked. The condition has been transmitted directly through three generations with no skipping and it affects both males and females. It is therefore concluded that, in this family, reduced ability to pronate and supinate the forearm is inherited as an autosomal dominant with variable expressivity. The anatomical anomaly appears to be different from any heretofore described.

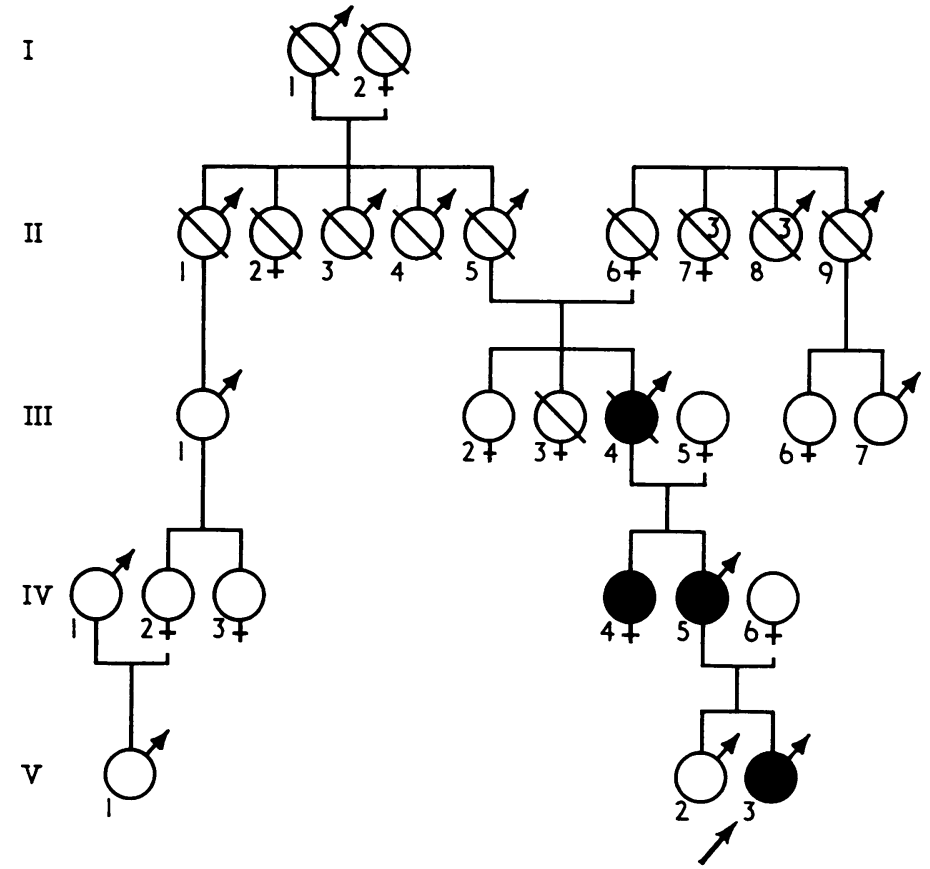

Fig. 3. Pedigree of family. Deceased members are shown with a bar through the figure. 


\section{Summary}

Four members of three generations of a Canadian family exhibit or exhibited an inability to pronate and supinate the forearm normally. The condition varies in severity from one member to another but there is surprisingly little functional disability. $X$-ray findings suggest flattening of the radial head in all living affected subjects. There is no displacement of the radial head, no abnormal curvature of the radial shaft, and no synostosis. No other portion of the body is affected.
The condition is inherited as an autosomal dominant with variable expressivity.

\section{REFERENCES}

Cockshott, W. P., and Omololu, A. (1958). Familial congenital posterior dislocation of both radial heads. F. Bone $f_{t}$ Surg., 40-B, 483.

Davenport, C. B., Taylor, H. L., and Nelson, L. A. (1924). Radioulnar synostosis. Arch. Surg., 8, 705.

Gunn, D. R., and Pillay, V. K. (1964). Congenital posterior dislocation of the head of the radius. In Clinical Orthopedics and Related Research, ed. A. F. De Palma, Vol. 34, p. 108. Pitman, London; Lippincott, Philadelphia. 